\title{
PRÓPOLIS: 100 ANOS DE PESQUISA E SUAS PERSPECTIVAS FUTURAS
}

\author{
Alberto dos Santos Pereira, Fernando Rodrigues Mathias Silva Seixas e Francisco Radler de Aquino Neto* \\ Instituto de Química, Universidade Federal do Rio de Janeiro, Ilha do Fundão, Cidade Universitária, 21949-900 Rio de Janeiro - RJ
}

Recebido em 22/1/01; aceito em 25/7/01

\begin{abstract}
PROPOLIS: 100 YEARS OF RESEARCH AND FUTURE PERSPECTIVES. Propolis is a multifunctional material used by bees in the construction and maintenance of their hives. The chemical composition and pharmacological properties have been studied for centuries. Today they represent an important raw material for many health products and constitute a new interdisciplinary area for research. Among others they show important antimicrobial and cytotoxic activities and various pharmacological properties. This paper presents an overview of the scientific literature and patents concerning propolis.
\end{abstract}

Keywords: propolis; patents; chemical composition; biological activity.

\section{INTRODUÇÃo}

Ao longo da história, o homem apreendeu a utilizar os produtos naturais na medicina. Uma revisão recente sobre esse assunto foi apresentada em Química Nova por Barreiro. Das várias formas de utilização destacam-se as plantas brutas (ex.: ervas) além das tradicionais preparações Galênicas (ex.: extratos). Um dos muitos produtos naturais utilizados durante séculos pela humanidade tem sido a própolis (CAS No. 9009-62-5) administrada sob diversas formas. Seu emprego já era descrito pelos assírios, gregos, romanos, incas e egípcios. No antigo Egito (1700 A.C.; "cera negra") era utilizada como um dos materiais para embalsamar os mortos.

A própolis é uma mistura complexa, formada por material resinoso e balsâmico coletada pelas abelhas dos ramos, flores, pólen, brotos e exsudados de árvores; além desses, na colméia as abelhas adicionam secreções salivares ${ }^{2-5}$. Vários trabalhos têm sido publicados divulgando e revisando as propriedades biológicas da própolis como, por exemplo, as antimicrobiana, antifúngica, antiprotozoária, antioxidante e antiviral ${ }^{4-6}$. Na África do Sul, na guerra ao final do século XIX, foi amplamente utilizada devido às suas propriedades cicatrizantes $^{5}$ e na segunda guerra mundial foi empregada em várias clínicas soviéticas ${ }^{7}$. Na antiga URSS, a própolis mereceu especial atenção em medicina humana e veterinária, com aplicações inclusive no tratamento da tuberculose, observando-se a regressão dos problemas pulmonares e recuperação do apetite ${ }^{8}$.

Os gregos, entre os quais Hipócrates, a adotaram como cicratizante interno e externo. Plínio, historiador romano, refere-se à própolis como medicamento capaz de reduzir inchaços e aliviar dores $^{7}$. O termo própolis já era descrito no século XVI na França ${ }^{5}$ e, em 1908 surgiu o primeiro trabalho científico ${ }^{9}$ sobre suas propriedades químicas e "composição", indexado no Chemical Abstracts (referência ${ }^{\circ}$ 192). Em 1968 surgiu no Chemical Abstracts o resumo da primeira patente utilizando a própolis ${ }^{10}$ (Romena, para a produção de loções para banho).

Historicamente o primeiro trabalho ${ }^{9}$ (indexado pelo Chemical Abstracts) sobre a própolis foi publicado 10 anos depois que o professor Heinrich Dresser da Bayer, proclamou o surgimento de uma milagrosa droga batizada como heroína; 5 anos depois do surgimento

* e-mail: ladetec@iq.ufrj.br. do primeiro barbitúrico e 14 anos antes do descobrimento da vitamina $\mathrm{D}$, por McColumn e colaboradores, no óleo de fígado de bacalhau (que evitaria e curaria o raquitismo), isolada na Alemanha por Windaus (agraciado por isso com o prêmio Nobel) ${ }^{11}$.

Em pouco mais de 90 anos, o número de trabalhos publicados citados no Chemical Abstracts totaliza 450, oriundos de 39 países (dos cinco continentes), além de 239 patentes.

\section{PUBLICAÇÕES}

A Figura 1 mostra o comportamento de crescimento quase exponencial do número total de publicações sobre a própolis. Todos os principais países em número de publicações no assunto tiveram um aumento substancial nas décadas de 80 e 90: entre $40 \%$ (Itália de 5 para 7 trabalhos publicados) e $660 \%$ (Japão de 5 para 38 trabalhos publicados). Com exceção da Polônia e da Bulgária que tiveram respectivamente um aumento de $53 \%$ e $47 \%$ de produtividade entre as décadas de 80 e 90 (respectivamente 13 para 20 e 17 para 25 trabalhos publicados), todos os outros países do antigo bloco comu-

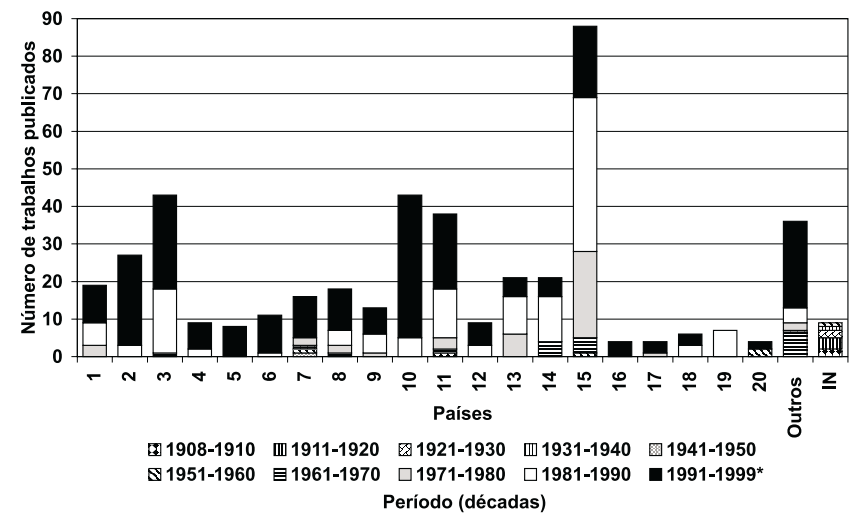

Figura 1. Produtividade científica sobre a própolis entre as décadas de 10 e de 90 (fonte "Chemical Abstracts"); 1 = Alemanha; $2=$ Brasil; $3=$ Bulgária; 4 = China; $5=$ Cuba; $6=$ Espanha; $7=$ Estados Unidos; $8=$ França; $9=$ Itália $; 10=$ Japão $; 11=$ Polônia $; 12=$ Reino Unido; $13=$ Republica Checa; 14 = Romênia $; 15=$ Rússia $; 16=$ Egito $; 17=$ Holanda ; 18 = Iugoslávia $; 19=$ Hungria $; 20=$ Ucrânia e IN = Artigo cujo país de origem não foi determinado 
Tabela 1. Relação de algumas propriedades "biológicas" da própolis em ordem cronológica

\begin{tabular}{|c|c|c|}
\hline Data & País & Propriedade farmacológica estudada na própolis \\
\hline 1957 & URSS & Uso como anestésico $^{11}$ \\
\hline 1967 & Romênia & Uso no tratamento dermatológico, com ação antifúngica ${ }^{12}$ \\
\hline 1968 e 1981 & URSS & Uso no tratamento de úlceras (em ratos) $)^{13,14}$ \\
\hline 1968 & Polônia & Estudo das propriedades bactericidas (gênero Candida) ${ }^{15}$ \\
\hline 1976 & Alemanha & Antifúngicas (ex.: Scopulariopsis brevicaulis) ${ }^{16}$ \\
\hline 1976 e 1977 & Polônia & Antiprotozoários (ex: Trichomonas vaginalis e Toxoplasma gondii) ${ }^{17,18}$ \\
\hline 1981 & URSS & Antibióticos (Staphylococus aureus) ${ }^{19}$ \\
\hline 1983 & Iugoslávia & Atividade citotóxica in vitro de EEP (de células HeLa, carcinoma cervical humano) ${ }^{20}$ \\
\hline 1984 & Brasil & Antibióticos (Staphylococus aureus) $)^{20}$ \\
\hline 1985 & Iugoslávia & Inibidor de Bacilus subtilis (IP-5832) ${ }^{22}$ \\
\hline 1986 & Tchecoslováquia & Inibidor de RNA polimerase de Escherichia coli e Streptomyces aurofaciens ${ }^{23}$ \\
\hline 1989 & Polônia & Antitumoral (carcinoma de Ehrlich) ${ }^{24}$ \\
\hline 1990 & Itália & Inibição de vários vírus (ex.: herpes) ${ }^{25}$ \\
\hline 1992 & Bulgária & Inibição do vírus Influenza $\mathrm{A}^{26}$ \\
\hline 1993 & EUA & Antitumoral (testado em ratos e bovinos) ${ }^{27}$ \\
\hline 1995,1996 e 1998 & Japão & Citotoxidade da própolis brasileira ${ }^{28-30}$ \\
\hline 1994 e 1995 & Brasil & Atividade contra Trypanosoma cruzi $^{31,32}$ \\
\hline 1998 & Eslováquia & Antimutagênico ${ }^{33}$ \\
\hline 1999 & Brasil & $\begin{array}{l}\text { Várias contribuições apresentadas no I Simpósio Brasileiro Sobre Própolis e Apiterápicos } \\
\text { (realizado na Universidade de Franca, } 18 \text { a } 21 \text { de agosto de 1999) }\end{array}$ \\
\hline
\end{tabular}

nista europeu apresentaram um decréscimo da produtividade, coincidindo com o colapso dos regimes comunistas no leste europeu.

$\mathrm{O}$ interesse global de pesquisas em própolis tem duas justificativas: a primeira devido a suas características de panacéia (Tabela 1). De certa maneira essas características também atrapalham sua aceitação, já que os médicos e outros profissionais tendem a desconfiar de sua eficácia devido a lhe serem atribuídas dezenas de atividades biológicas simultaneamente. O segundo é devido a seu alto valor agregado, pelo qual um frasco do extrato alcoólico é vendido no Brasil por cerca de 5 a 10 reais, mas chegando a custar 150 Dólares em Tóquio ${ }^{34}$. Este alto valor agregado em Tóquio pode justificar em parte o interesse dos japoneses na própolis, principalmente a brasileira (sendo hoje a terceira maior produção mundial, perdendo apenas para a Rússia e a China). Embora produza de 10 a $15 \%$ da produção mundial, o Brasil atende a cerca de $80 \%$ da demanda japonesa ${ }^{35}$. Dados da Federação de Apicultores de Minas Gerais revelam que a própolis produzida no Estado é considerada a melhor do mundo no mercado japonês, onde o quilograma do produto saltou de US\$ 5 para US\$ 200 nos últimos anos ${ }^{36}$.

Dois pontos se destacam na preferência japonesa pela própolis brasileira (obviamente além das propriedades farmacológicas): o primeiro em relação às suas características organolépticas e em segundo devido ao menor teor de metais pesados e demais poluentes ambientais $^{37}$.

$\mathrm{O}$ interesse dos japoneses pela própolis é traduzido no número de publicações. Em 1987 surgiram as três primeiras publicações japonesas; coincidentemente, todas revisando em japonês as suas propriedades, principalmente as biológicas ${ }^{37-39}$. Após 12 anos o Japão já responde por cerca de $10 \%$ do total de trabalhos publicados, somente atrás da Rússia (19\%, principalmente devido a produtividade da antiga URSS), Figura 2.

No Brasil a primeira publicação sobre a própolis, em 1984, apresenta um estudo comparativo do efeito da própolis e antibióticos na inibição de Staphylococcus aureus. A própolis brasileira estudada apresentou mais atividade do que vários antibióticos testados ${ }^{20}$. Apesar da posição de destaque na produção e comércio da própolis, e de possuir a quinta maior produtividade científica no assunto (cerca de
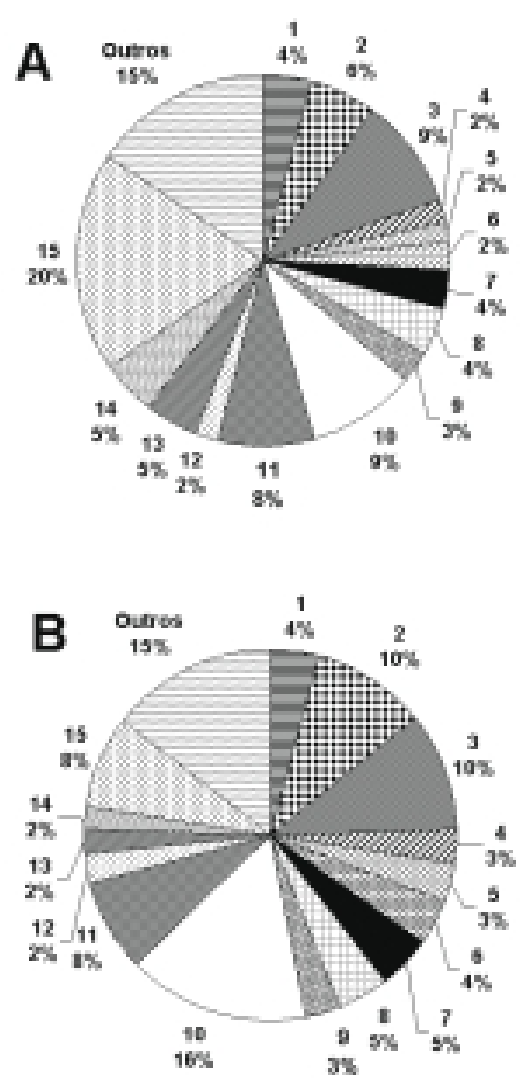

Figura 2. A) Produtividade científica sobre a própolis entre os anos de 1908 e 1999 em relação aos países de origem (fonte "Chemical Abstracts”). B) Produtividade científica referente a década de 90 em relação aos países de origem (fonte "Chemical Abstracts"); 1 = Alemanha; 2 = Brasil; $3=$ Bulgária; $4=$ China; $5=$ Cuba; $6=$ Espanha; $7=$ Estados Unidos; $8=$ França 9 = Itália $; 10=$ Japão; 11 = Polônia $; 12=$ Reino Unido $; 13=$ Republica Checa; 14 = Romênia $; 15=$ Rússia $; 16=$ Ucrânia e IN = Artigo cujo país de origem não foi determinado 
6\% do total de trabalhos publicados, 27 artigos, Figura 2), a atividade de pesquisa no Brasil não reflete em número, nem em conteúdo, o interesse internacional que a própolis brasileira possui, principalmente para os japoneses.

\section{PATENTES}

Uma verdadeira "febre" de patentes vem sendo observada. Desde a primeira patente (romena) em $1965^{\circ}$ até 1999 já foram depositadas cerca de 239 patentes (Figura 3). Até o final da década de 80 as patentes eram dominadas pela antiga URSS e seus países satélites, principalmente a Romênia. Hoje $43 \%$ de todas as patentes depositadas são japonesas (Figura 4), sendo que a primeira patente japonesa surgiu somente em 1987 (sobre o uso da própolis no controle de odores $)^{40}$. Em relação ao Brasil a primeira patente surgiu somente em 1995 para o uso em tratamento odontológico ${ }^{41}$, na prevenção de cáries e gengivites. Até 1999 o Brasil possuía somente cerca de 3 patentes (menos de $2 \%$ de todas as patentes depositadas). As patentes brasileiras e algumas de outros países patentes são apresentadas na Tabela 2.

Quinze patentes, 6,2\% das patentes depositadas até o começo de 1999, referem-se ao uso da própolis no tratamento odontológico (ver Tabela 3). Essa é uma das aplicações da própolis mais estudada em todo mundo, tendo relatos científicos desde $1952^{42}$. Um dos mecanismos importantes da própolis na redução da incidência da cárie dental é através da inibição das enzimas glicosiltransferases, além de inibir o crescimento dos patógenos bucais ${ }^{43-44}$.

$\mathrm{O}$ reduzido número de patentes brasileiras em relação aos trabalhos publicados ( 3 patentes/27 trabalhos publicados), reflete infelizmente o fato da universidade brasileira não ter o hábito de proteger suas atividades de pesquisa por meio de patentes (o uso de patentes

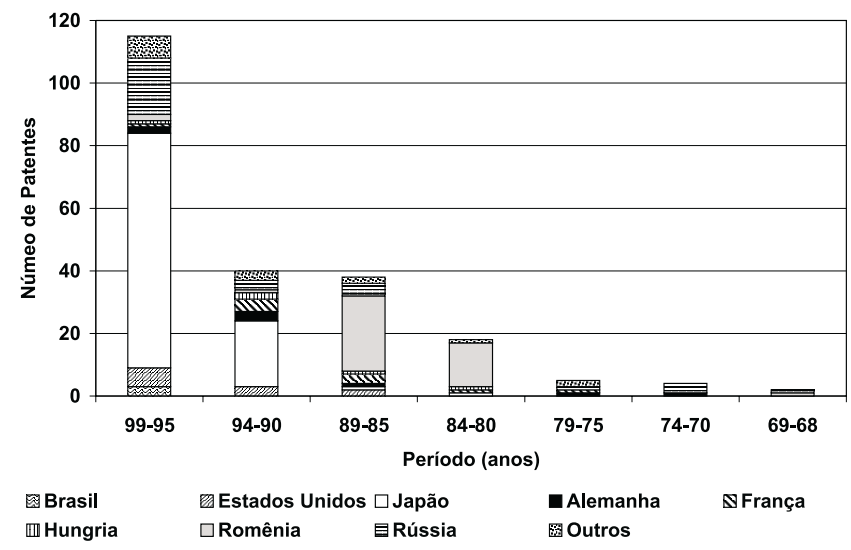

Figura 3. Patentes depositadas sobre a própolis entre os anos de 1965 e 1999 (fonte "Chemical Abstracts") no Brasil é discutido em detalhes por Rodrigues em Química Nova ${ }^{45}$ ). O oposto ocorre no Japão, onde foram depositadas 98 patentes, mais do dobro do número de trabalhos publicados (43) no mesmo período, incluindo patentes sobre a aplicação de compostos isolados inicialmente de amostras da própolis brasileira. Esse fato deveria despertar a atenção da comunidade científica nacional, para não se repetir os erros do passado, ocasião em que ocorreu o mais famoso e provavelmente primeiro caso de "biopirataria", atribuído ao inglês Henry Wickhan, que em 1876, contrabandeou para os jardins reais de Kew, em Londres, mais de 70 mil sementes de seringueira. Passados 30 anos, o cultivo da seringueira se expandiu nos países asiáticos, patrocinado pelos ingleses, e houve a quebra do monopólio da
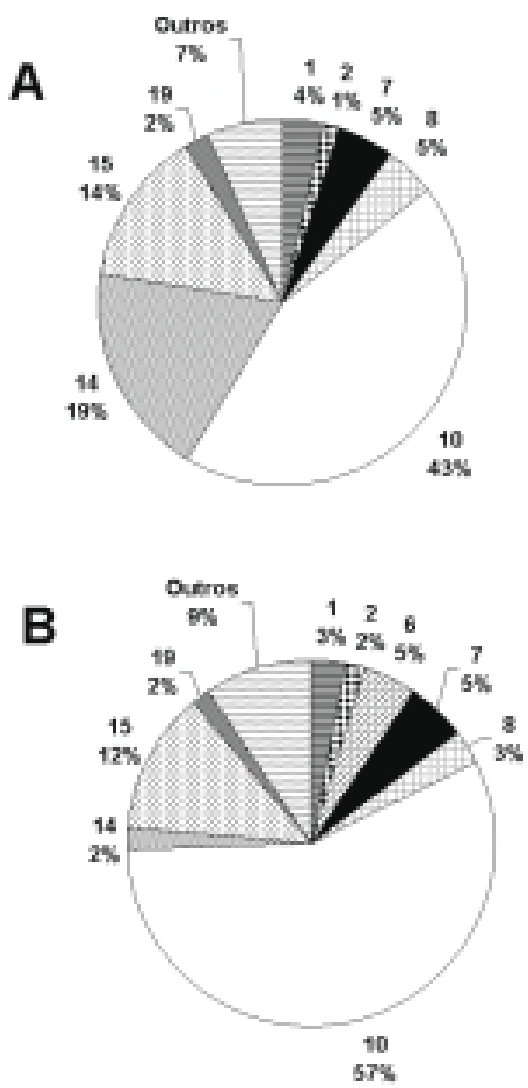

Figura 4. A) Patentes depositadas sobre a própolis em relação aos países de origem (fonte "Chemical Abstracts”). B) Patentes depositadas, na década de 90, sobre a própolis em relação aos países de origem (fonte "Chemical Abstracts”); 1 = Alemanha; 2 = Brasil; $6=$ Espanha; 7 = Estados Unidos; $8=$ França $; 10=$ Japão $; 14=$ Romênia $; 15=$ Rússia $; 19=$ Hungria

Tabela 2. Relação de algumas das 239 patentes internacionais

\begin{tabular}{llll}
\hline Ano & País & Título & Registro \\
\hline 1982 & Romênia & "Drug for treatment of prostate cancer" & RO 87149 \\
1983 & Romênia & "Choline-containing drugs for the treatment of hepatitis" & RO 88869 \\
1992 & Romênia & "Hydrophilic gel with antiviral action against herpetic infections of skin and mucosa" & RO 106658 \\
1995 & Japão & "Antitumor benzopyran derivative of propolis" & JP 09143179 \\
& & & WO 9829404 \\
1997 & França & "Natural products containing propolis and essential oils for use in cosmetics and pharmaceuticals" & FR 2767061 \\
1997 & Japão & "Propolis-containing cellulose for improvement of digestive tract functions" & JP 10215815 \\
1997 & Japão & "Extracts of agarics and/or propolis, and Amazon enzymes as natural food preservatives" & JP 10215838 \\
1997 & Japão & "Anti-Helicobacter pylori agents having lower toxicity" & JP 11106335 \\
\hline
\end{tabular}


Tabela 3. Relação das patentes na área odontológica

\begin{tabular}{llll}
\hline Ano & País & Título & Registro \\
\hline 1967 & URSS & "Toothpaste" & SU 232470 \\
1970 & URSS & "Preparation for treating diseases of oral cavity mucosa" & SU 267014 \\
1972 & Alemanha & "Composition for treating periodontopathy" & DD 100157 \\
1974 & Alemanha & "Pharmaceutical preparation for treatment of dermatological diseases" & DD 109511 \\
1983 & Romênia & "Composition for treatment of the diseases of dental pulp" & RO 87151 \\
1986 & URSS & "Toothpaste" & SU 12663247 \\
1988 & Japão & "Propolis-containing antibiotic ointments for atopic dermatitis treatment" & JP 02142734 \\
1989 & URSS & "Method for protecting dentures" & SU 1697808 \\
1994 & Espanha & "Multiple-use dermatological cream" & ES 2080697 \\
1995 & Brasil & "Dental gel" & BR 9503177 \\
1995 & Japão & "Dentifrices containing propolis for prevention or treatment of periodontosis" & JP 08325129 \\
1996 & Brasil & "Prophylactic and theraupeutic dental cream propolis formulation" & BR 9604085 \\
1996 & China & "Toothpaste for dental care and tooth whitening" & CN 1171929 \\
1998 & Japão & "Tooth coating composite and its preparation" & EP 900560 \\
1998 & Israel & "Local oral herbal slow release tablets" & WO 9906030 \\
\hline
\end{tabular}

produção da Amazônia. Hoje, pagamos pela histórica falta de controle do governo brasileiro sobre nossa biodiversidade, e como consequiência de único produtor mundial a importadores de cerca de 100.000 t/ano de borracha natural.

\section{BIODIVERSIDADE E COMPOSIÇÃO QUÍMICA DA PRÓPOLIS}

Hoje a própolis vem sendo largamente empregada na medicina popular, em cosméticos e dermocosméticos ${ }^{36,46,47}$.

As propriedades biológicas da própolis obviamente estão diretamente ligadas a sua composição química, e este possivelmente é o maior problema para o uso da própolis em "fitoterapia", tendo em vista que a sua composição química varia com a flora da região e época da colheita, com a técnica empregada, assim como com a espécie da abelha (no caso brasileiro também o grau de "africanização" da Apis melífera pode influenciar a sua composição) ${ }^{47}$. Somente no caso do Brasil são descritas propriedades biológicas e composição química distintas para diferentes amostras coletadas em diferentes partes do país ${ }^{48-60}$. Essa variação é facilmente explicada pela grande biodiversidade brasileira. Uma menor variação da composição química da própolis é observada nas regiões temperadas do planeta, como por exemplo na Europa, onde seus principais compostos bioativos são os flavonóides (flavonas, flavonóis e flavononas), sendo a crisina (5,7-diidroxiflavona) o primeiro flavonóide isolado em 1927 da própolis cuja fonte vegetal é Populus nigra var. pyramidalis ${ }^{61}$.

Há grande controvérsia em relação ao teor de flavonóides nas amostras brasileiras nas quais os ácidos fenólicos são geralmente bem mais abundantes. Em relação aos resultados obtidos em nosso laboratório, somente uma (coletada em 1996, em Guarapari, Estado do Espírito Santo, provavelmente associada à flora do gênero Cambará) em um total de 14 amostras de própolis das regiões sul e sudeste do Brasil, apresentou alto teor de flavonóides ${ }^{60}$.

Grumberger et $a l .{ }^{62}$ descrevem o cafeato de feniletila (CAPE) como um composto responsável pelas propriedades citotóxicas da própolis oriunda das montanhas "Carmel", Israel. Segundo Banskota et al. ${ }^{58}$ os principais ácidos aromáticos encontrados na própolis brasileira são o 3-prenil-4-hidroxicinâmico e o 6-propenóico-2,2-dimetil2H-1-benzopirano, dentre outros. Vários outros compostos bioativos vêm sendo isolados na própolis brasileira. Pode-se destacar os diterpenóides (clerodanos) com atividade citotóxica ${ }^{29,63}$ e derivados do ácido di-O-cafeoil-quínico com potente atividade antihepatotóxica ${ }^{53,54}$.
Hoje mais de 300 constituintes já foram identificados e/ou caracterizados em diferentes amostras de própolis, dentre eles: flavonóides, ácidos aromáticos, ácidos graxos, fenóis, aminoácidos, vitaminas $\mathrm{A}, \mathrm{B}_{1}, \mathrm{~B}_{2}, \mathrm{~B}_{6}, \mathrm{C}, \mathrm{E}$ e PP (encontradas na própolis de ori-

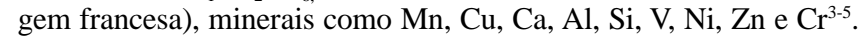
Mais de 250 desses compostos foram relacionados por Marcucci em Química Nova ${ }^{5}$. Mais recentemente, com a evolução das técnicas de análise, compostos de alta massa molecular e carboidratos (incluindo polissacarídeos) foram relatados ${ }^{60,64,65}$.

Os resultados de análises de 13 amostras das regiões sul e sudeste do Brasil (Figuras 5 a 9) estudadas segundo o protocolo publicado em Pereira, et al. ${ }^{60}$, ilustram a variação da composição química das própolis brasileiras. Comparando simplesmente as massas dos extratos obtidos, pode-se observar uma grande variação para diferentes amostras de própolis mostrando a diversidade de composição dessas própolis brutas. Observações análogas são válidas para diferentes classes de compostos, desde os ésteres graxos até o ácido cinâmico e compostos correlatos, demonstrando assim que as própolis brasileiras necessitam de mais estudos.

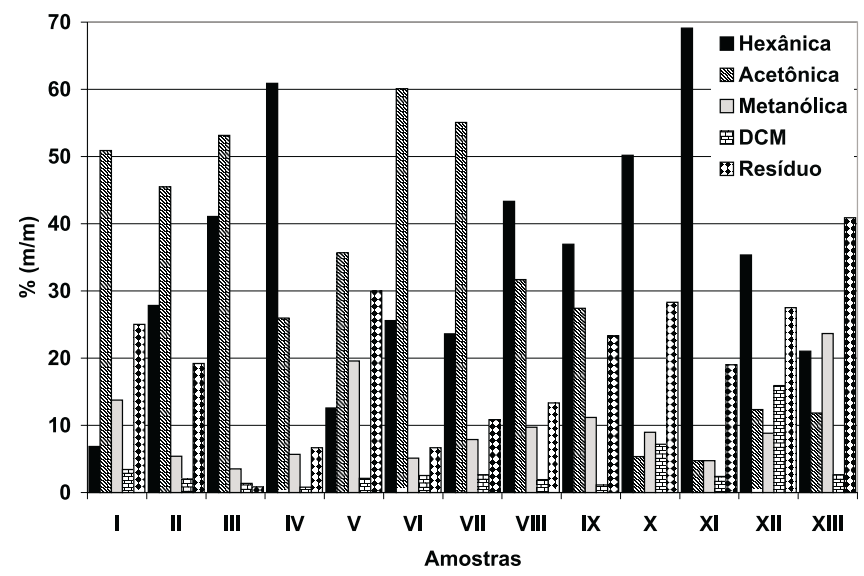

Figura 5. Massas dos extratos obtidos em diferentes amostras de própolis brasileiras coletadas em I = Tunas do Paraná; $I I=$ Visconde de Mauá $(R J)$; $I I I=$ Bonfim $(M G) ; I V=$ Nova Friburgo $(R J) ; V=$ Santo Antônio do Pinhal $(S P) ; V I=$ Rio de Janeiro $(R J) ; V I I=$ Santa Catarina $;$ VIII = Freguesia $(R J) ; I X=$ Frederico Westphalen $(R S) ; X=$ Bituruna $(P R) ; X I=$ Friburgo $(R J) ; X I I=$ Barra do Pirai $(R J)$ e XIII = Nova Friburgo $(R J) . D C M=$ extrato obtido com diclorometano, detalhes da extração na ref. 60 


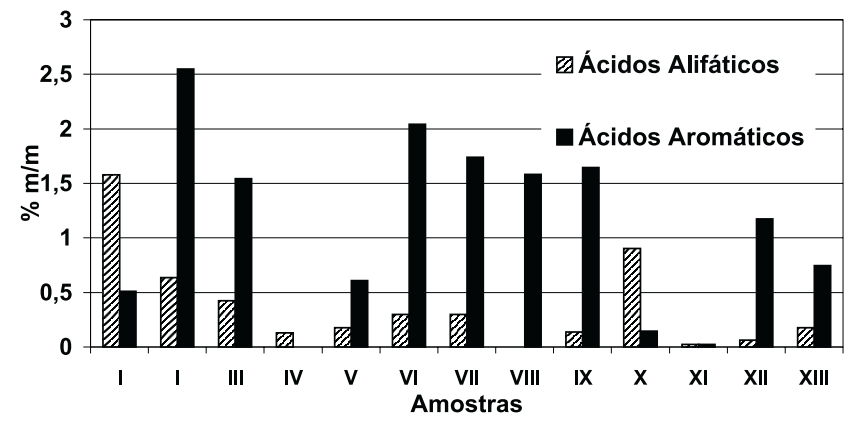

Figura 6. Ocorrência de ácidos alifáticos e aromáticos (com exceção dos cinâmicos e compostos correlatos) em diferentes amostras de própolis brasileiras coletadas em $I=$ Tunas do Paraná; $I I=$ Visconde de Mauá $(R J)$; $I I I=$ Bonfim $(M G) ; I V=$ Nova Friburgo $(R J) ; V=$ Santo Antônio do Pinhal $(S P) ; V I=$ Rio de Janeiro $(R J) ; V I I=$ Santa Catarina $; V I I I=$ Freguesia $(R J) ; I X=$ Frederico Westphalen $(R S) ; X=$ Bituruna $(P R) ; X I=$ Friburgo $(R J) ; X I I=$ Barra do Pirai $(R J)$ e XIII = Nova Friburgo $(R J)$

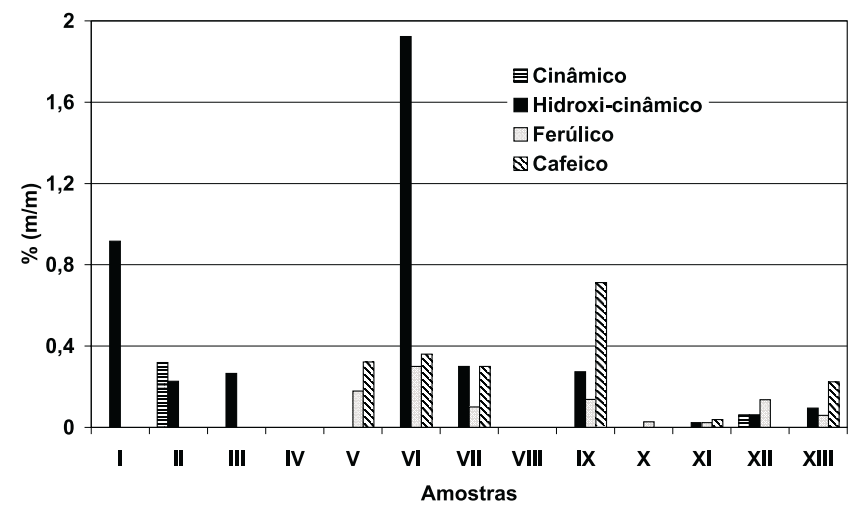

Figura 7. Ocorrência de ácido p-hidroxi-cinâmico e compostos correlatos em diferentes amostras de própolis brasileiras coletadas em $I=$ Tunas do Paraná; $I I=$ Visconde de Mauá (RJ); III = Bonfim $(M G) ; I V=$ Nova Friburgo $(R J) ; V=$ Santo Antônio do Pinhal $(S P) ; V I=$ Rio de Janeiro $(R J) ; V I I=$ Santa Catarina; VIII = Freguesia $(R J) ; I X=$ Frederico Westphalen $(R S) ; X$ $=$ Bituruna $(P R) ; X I=$ Friburgo $(R J) ; X I I=$ Barra do Pirai $(R J)$ e XIII $=$ Nova Friburgo $(R J)$

\section{PERSPECTIVAS FUTURAS}

Não se pode relegar a própolis a uma categoria de modismo terapêutico, tendo em vista que suas virtudes são reconhecidas há séculos, sendo relatadas em inúmeros trabalhos que demonstram diferentes tipos de atividade biológica e aplicações em diversas terapias, principalmente na área odontológica. Em Cuba, foram realizados vários estudos clínicos (em dermatologia, como antibiótico e modificador de resposta biológica entre outras aplicações) ${ }^{66}$ bem como no Brasil no uso pré- e pós-operatório ${ }^{67}$ e tratamento de hiperglicemias (diabetes) ${ }^{68}$.

A grande questão para o futuro é responder a uma pergunta antiga: qual própolis serve para qual ação terapêutica? E para isso é necessário definir quais parâmetros terapêuticos mínimos as diferentes própolis devem possuir, ou idealmente qual composição química mínima deveria ser exigida para que apresentem as propriedades farmacológicas desejadas. No caso da própolis européia a padronização de seu uso como "fitoterápico" é mais simples já que o principal parâmetro que rege sua atividade é o teor de flavonóides. Portanto, determinando o teor de flavonóides e contaminantes (como metais pesados) seria possível classificar a qualidade da própolis.

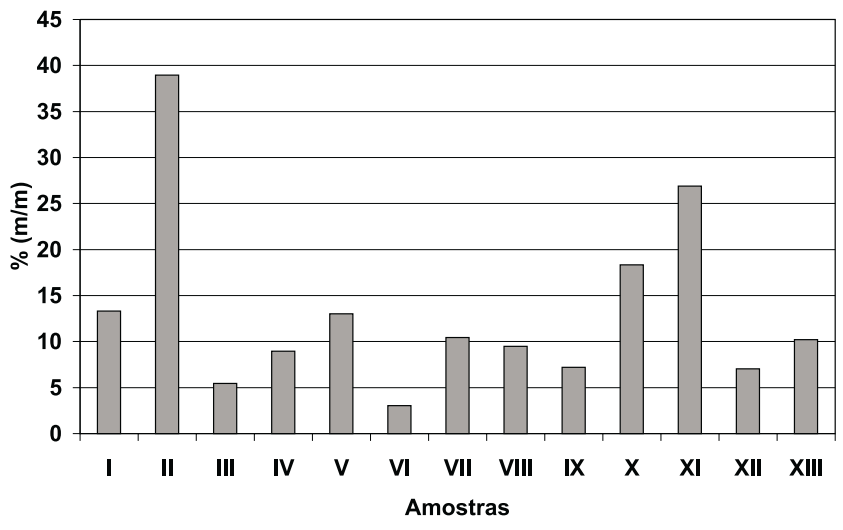

Figura 8. Ocorrência de ésteres de alta massa molecular em diferentes amostras de própolis brasileiras coletadas em $I=$ Tunas do Paraná; $I I=$ Visconde de Mauá (RJ); III = Bonfim $(M G) ; I V=$ Nova Friburgo $(R J) ; V=$ Santo Antônio do Pinhal (SP); VI = Rio de Janeiro (RJ); VII = Santa Catarina $;$ VIII $=$ Freguesia $(R J) ; I X=$ Frederico Westphalen $(R S) ; X=$ Bituruna $(P R) ; X I=$ Friburgo $(R J) ; X I I=$ Barra do Pirai $(R J)$ e XIII = Nova Friburgo (RJ)

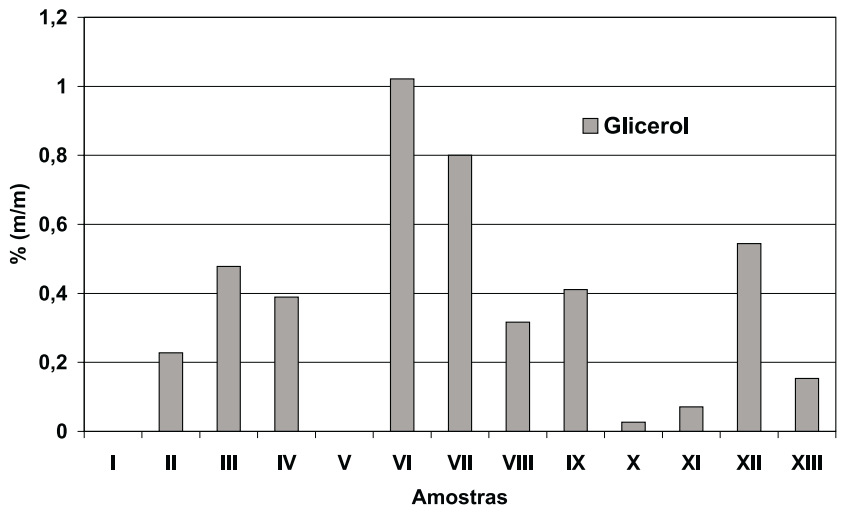

Figura 9. Ocorrência de glicerol em diferentes amostras de própolis brasileiras coletadas em I = Tunas do Paraná; $I I$ = Visconde de Mauá $(R J)$; $I I I=$ Bonfim $(M G) ; I V=$ Nova Friburgo $(R J) ; V=$ Santo Antônio do Pinhal $(S P) ; V I=$ Rio de Janeiro $(R J) ; V I I=$ Santa Catarina $;$ VIII = Freguesia $(R J) ; I X=$ Frederico Westphalen $(R S) ; X=$ Bituruna $(P R) ; X I=$ Friburgo $(R J) ; X I I=$ Barra do Pirai $(R J)$ e XIII = Nova Friburgo $(R J)$

Atualmente, na comunidade de apicultores brasileiros existe a preocupação de o Brasil perder mercado, caso não haja uma padronização das características da própolis brasileira ${ }^{69}$.

A caracterização da qualidade da própolis brasileira é um desafio multidisciplinar que a comunidade científica tem pela frente, tendo em vista a variação de composição e o grande número de compostos bioativos. É necessário determinar quais são os parâmetros que devem ser controlados para que a própolis comercial possua uma determinada atividade farmacológica. Essa preocupação não é novidade, e vem sendo defendida há algum tempo no Brasil, por Marcucci e colaboradores ${ }^{70}$.

\section{AGRADECIMENTOS}

À FAPERJ, FUJB e CNPq por auxílios a pesquisa e bolsas concedidas.

\section{REFERÊNCIAS}

1. Barreiro, E.J.L.; Quim. Nova 1990, 13, 29.

2. Ghisaberti, E.L.; Bee World 1979, 60, 59.

3. Vanhaelen, M.; Vanhaelen-Fastré, R.; J. Pharm. Belg. 1979, 34, 253. 
4. Marcucci, M.C.; Apidologie 1995, 26, 83.

5. Marcucci, M.C.; Quim. Nova 1996, 19, 529.

6. Burdock, G.A.; Food Chem. Toxicol. 1998, 36, 347.

7. Ioirish, N.; As Abelhas: Farmacêuticas com Asas, Editora Mir: Moscou, 1982; p. 228.

8. Woisky, R.G.; Giesbrecht, A.M.; Salatino, A.; Rev. Farm. Bioquím. Univ. S. Paulo 1994, 30, 19.

9. Helfenberg, K.D.; Chem. Ztg. 1908, 31, 987.

10. Iuliu, P.; Patente No. RO 481011965.

11. Silverman, M.; Magia em Garrafas: A História dos Grandes Medicamentos, Companhia Editora Nacional: São Paulo, 1943, p. 280.

12. Prokopovich, N.N.; Vrachebneo Delo 1957, 10, 1077.

13. Popescu, A.; Braleanu, C.; Gheorghiu, A.; Derm. Venerol. 1967, 12, 57.

14. Aripov, K.A.; Kamilov, I.K.; Aliev, K.U.; Med. Zh. Uzb. 1968, 5 , 50.

15. Abdullaev, N.K.; Latipov, A.; Rasulev, N.I.; Shakhabutdinov, Z.S.; Med. Zh. Uzb. 1981, 9, 24

16. Scheller, S.; Rogata, D.; Stasiak, E.; Zurek, H.; Pol. Arch. Wet. 1968, 11, 391 .

17. Metzner, J.; Bekemeier, H.; Schneidewind, E.; Schwaibwerger, R.; Pharmazie 1975, 30, 799.

18. Metzner, J.; Schneidewind, E.; Friedrich, E.; Pharmazie 1977, 32, 730.

19. Starzyk, J.; Scheller, S.; Szaflarki, J.; Moskwa, M.; Stojko, A.; Arzenein. Forsch. 1977, 27, 1198.

20. Shub, T.A.; Kagramanova, K.A.; Voropeava S.D.; Kivman, G.Y.; Antibiotiki 1981, 26, 268.

21. Ban, J.; Popovic, S.; Maysinger, D.; Acta Pharm. Jugosl. 1983, 33, 245.

22. Szewczak, E.H.; Godoy, G.F.; Chociai, J.G.; Aerosol Cosmet. 1984, 6, 12.

23. Pepeljnak, S.; Jalsenjak, I.; Maysinger, D.; Pharmazie 1985, 40, 122.

24. Simuth, J.; Trnovsky, J.; Jelokova J.; Pharmazie 1986, 41, 131.

25. Scheller, S.; Krol, W.; Swiacik, J.; Owczarek, S.; Gabrys, J.; Shani, J.; Z. Naturforch. 1989, 44, 1063.

26. Debiaggi, M.; Tateo, F.; Pagani, L.; Luini, M.; Romero, E.; Microbiologica 1990, 13, 207.

27. Sekendzhieva, Y.; Manolova, N.; Bankova, V.; J. Nat. Prod. 1992, 55, 294.

28. Frenkel, K.; Wei, H.; Bhimani, R.; Ye, J.; Zadunaisky, J.A.; Huang, M.T.; Ferraro, T.; Conney, A.H.; Dedizer, G.; Cancer Res. 1993, 53, 1255.

29. Matsuno, T.; Z. Naturforsch 1995, 50c, 93.

30. Suzuki, I.; Takai, H.; Koide, M.; Yamamoto, H.; Mitsubachi Kagaku 1996, 17,1 .

31. Banskota, A.H.; Tezuka, Y.; Prasain, J.K.; Matsushige, K.; Saiki, I.; Kadota, S.; J. Nat. Prod. 1998, 61, 896.

32. Higashi, K.O.; Castro, S.L.; J. Ethnopharmacol. 1994, 43, 149.

33. Castro, S.L.; Higashi, K.O.; J. Ethnopharmacol. 1995, 46, 55.

34. Cizmarik, J.; Lahitova, N.; Jelokova J.; Pharmazie 1998, 53, 883.

35. Nothenberg, M.; Química e Derivados 1997, 24.

36. Carvalho, R.B.; Ciência Hoje 2000, 27, 55.

37. Mizumo, M.; Iinuma, M.; Kato, H.; Fragrance J. 1987, 15, 20.

38. Kawai, Y. e Konichi, H.; Fragrance J. 1987, 15, 29

39. Kumo, K.; Fragrance J. 1987, 15, 36.

40. Cho, H.; Torii, M.; Kanamori, T.; Patente No. JP 632645161987.

41. Itice, N.T.; Patente No. BR 95031771995.

42. Jenko, A.; Austrian 1952, 172, 63.
43. Bretz, W.A.; Chiego Jr., D.J.; Marcucci, M.C.; Cunha, I.; Custodio, A.; Schneider, L.G.; Z. Naturforch. 1998, 53c, 1045.

44. Park, Y.K.; Koo, M.H.; Abreu, J.A.S.; Ikegagaki, M.; Cury, J.A.; Rosalen, P.L.; Curr. Microbiol. 1998, 36, 24.

45. Rodrigues, A.O.; Quim. Nova 1998, 21, 228

46. Hermann, G.H.; Bracamonte, J.A.; Aerosol \& Cosmet 1991, 75, 8.

47. Ramos, M.F.S.; Dissertação de Mestrado, Universidade Federal do Rio de Janeiro, Brasil, 1995.

48. Woisky, G.R.; Giesbrecht, A.M.; Salatino, A.; Rev. Farm. Bioquím. Univ. S. Paulo 1994, 30, 19

49. Bankova, V.; Christov, R.; Kujumgiev, A.; Marcucci, M.C.; Popov, S.; Z. Naturforsch 1995, 50c, 167.

50. Bankova, V.; Nikolova, N.; Marcucci, M.C.; Z. Naturforsch 1996, 51 b, 735

51. Marcucci, M.C.; Camargo, F.A.; Lopes, C.M.A.; Z. Naturforsch 1996, 51c, 11.

52. Bankova, V.; Marcucci, M.C.; Simova, S.; Nikolova, N.; Kujumgiev, A.; Popov, S.; Z. Naturforsch 1996, 51c, 277.

53. Basnet, P.; Matsushige, K.; Hase, K.; Kadota, S.; Namba, T.; Biol. Pharm. Bull. 1996, 19, 1479.

54. Basnet, P.; Matsuno, T.; Neidlein, R.; Z. Naturforsch 1997, 52c, 828.

55. Tatefuji, T.; Izumi, N.; Ohta, T.; Arai, S.; Ikeda, M.; Kurimoto, M.; Biol. Pharm. Bull. 1996, 19, 996.

56. Miyataka, H.; Nishiki, M.; Matsumoto, H.; Fujimoto, T.; Matsuka, M.; Satoh, T.; Biol. Pharm. Bull. 1997, 20, 496.

57. Miyataka, H.; Nishiki, M.; Matsumoto, H.; Fujimoto, T.; Matsuka, M.; Isobe A.; Satoh, T.; Biol. Pharm. Bull. 1997, 21, 723.

58. Banskota, A.H.; Tezuka, Y.; Prasain, J.K.; Matsushige, K.; Saiki, I.; Kadota, S.; J. Nat. Prod. 1998, 61, 896.

59. Marcucci, M.C.; Rodrigues, J.; Ferreres, F.; Bankova, V.; Groto, R.; Popov, S.; Z. Naturforsch 1998, 53c, 117.

60. Pereira, A.S.; Ramos, M.F.S.; Poças, E.S.C.; Dias, P.C.M.; Santos, E.P.; Silva, J.F.M.; Cardoso, J.N.; Aquino Neto, F.R.; Z. Naturforsch 1999, $54 c$, 117.

61. Jaubert, G.F.; Compt. Rend. 1927, 184, 1134.

62. Grunberger, D.; Banerjee, R.; Eisinger, K.; Experientia 1988, 44, 230

63. Matsuno, T.; Matsumoto, Y.; Saito, M.; Morikawa, J.; Z. Naturforsch 1997, $52 c, 702$.

64. Pereira, A.S.; Pinto, A.C.; Cardoso, J.N.; Aquino Neto, F.R.; Ramos, M.F.S.; Dellamora-Ortiz, G.M.; Santos, E.P.; J. High Resoln. Chromatogr. 1998, 21, 396.

65. Pereira, A.S.; Silva, J.F.M.; Kitzke, R.; Cardoso, J.N.; Aquino Neto, F.R.; Z. Naturforsch 1999, 54c, 1115.

66. González, J.S.; Resumos do I Simp. Bras. sobre Própolis e Apiterápicos, Rev. Univ. de Franca 1999, 7, 15.

67. Mujalli, L.; Resumos do I Simp. Bras. sobre Própolis e Apiterápicos, Rev. Univ. de Franca 1999, 7, 15.

68. Facchini, O.; Resumos do I Simp. Bras. sobre Própolis e Apiterápicos, Rev. Univ. de Franca 1999, 7, 55.

69. Pesquisa FAPESP, Abril de 2000, 35.

70. Marcucci, M.C.; Resumos do I Simp. Bras. sobre Própolis e Apiterápicos, Rev. Univ. de Franca 1999, 7, 17. 